\title{
Protection and Inheritance of the Korean Nationality Music
}

\author{
Hao Li \\ School of Music \\ Heihe University \\ Heihe, China 164300
}

\author{
Zuping $\mathrm{Xu}$ \\ School of Music \\ Heihe University \\ Heihe, China 164300
}

\begin{abstract}
It not only promotes the in-depth research on the Chinese Korean nationality music but also has a distinctly important practical significance on the development of music culture of Heilongjiang and the construction of overall framework through systematically analyzing the problems in inheriting the music culture of Korean nationality in Heilongjiang and researching the development trend of it.
\end{abstract}

Keywords-the Korean nationality music; protection; inheritance

\section{INTRODUCTION}

Heilongjiang province has abundant ethnic cultural resources. Among all the distinctive cultures and arts of the northern minorities, the Korean nationality music just like a gorgeous azalea blooms in the vast northern area. The Korean nationality has lived on the black land from generation to generation and has created colorful ethnic music cultures with Heilongjiang characteristics, which becomes an indispensable and important part of the Heilongjiang music culture. Nowadays, under the big background of the global economic integration and the cultural diversity, with the soaring development of Chinese economic modernization, the social communities of Korean nationality in Heilongjiang are collapsing. Because of losing the living soil, the traditional culture of Korean nationality in Heilongjiang gets into trouble in the period of social transition and is declining under the impact of the new pace of life and foreign culture. With the rapid development of global economic integration, the traditional culture of Chinese nationalities is suffering from the unprecedented impact and challenge.

\section{CURRENT Situation OF THE Music CUlture OF KOREAN NATIONALITY}

Because of the dispersing residence characteristics, the Korean nationality is easy to be assimilated by other nationalities. With a high urbanization level, most of the ethnic Korean people are engaged in the tertiary industry, like the wholesale and retail, accommodation and catering. They have advanced concepts easy to be influenced by the external cultures. Many students of the Korean nationality receive education in schools for Han nationality, directly resulting in the crisis in using the language and words of them. Besides, the "empty nest" of Korean nationality families has formed.

Fund project: Heilongiiang province art and science planning project; "Research on the Development of Folk Music of Korean Nationality in Heilongjiang Province" (2015C010).
Children work far away from the elders who need to raise their grandchildren. For example, in the Shangzhi city of Heilongjiang, according to the statistics, about 25,000 people, 29 primary schools, 2,500 to 3,000 students existed in the end of the 20th century; the number of students at an ethnic middle school reached up to 1,800 . In recent years, the number of school and students has decreased sharply, only one primary school with less than 150 students and less than 500 middle school students. Except for the population outflow, the impact of the strong mainstream culture is a more important reason. Many ethnic Korean people are at sea and lose confidence in the ethnic education and culture and get close to the mainstream culture consciously or unconsciously and send their children into the schools for Han nationality to receive education. Appreciable quantity of adolescents of the Korean nationality in Heilongjiang province have abandoned the language and words of their own nationality and have totally integrated in the system of Han culture. The disappearance of a language means the lost of a culture. The declination of education predicts the ethnic music culture and art cannot be inherited.

\section{MEASURES TO PROTECT AND INHERIT THE KOREAN NATIONALITY MUSIC}

\section{A. Base on the Spreading of Ethnic Culture and Let the Culture Take Root in the Masses}

It is the urgent need of protecting and inheriting the traditional culture of Korean nationality in the minority areas and an effective means to promote themselves by using the advantages through the interaction between the traditional culture of the Korean nationality and the Yanbian Museum to create the culture brand with the Korean ethnic characteristics. Therefore, it is necessary to base on the spreading of ethnic culture and display the folk customs of Korean nationality for citizens to participate and experience. Besides, enrich the display content, deepen the connotation and improve the services around and pay attention to the participation, entertainment and interestingness, making the Korean nationality museum into a cultural leisure place that integrates the education and the recreation. 


\section{B. Build Rich Carriers of Culture and Lively Inherit the Ethnic Culture}

As the footstone for the development of museum, in displaying the traditional culture of Korean nationality, the publicity and education needs to provide diversified services to attract the audience, and then stimulate people's potential learning desire, enhance their understanding for the traditional culture and improve their cultural literacy. Plentiful carriers of culture should be built in and outside the Yanbian Museum to lively inherit the traditional culture of Korean nationality. Holiday celebrations and anniversary celebrations should be used to hold folk artistic performances like Xiangmao dance, Changgu dance, Nongyue dance, Dongxiao (a vertical bamboo flute) and Jiajiaqin, regularly carry out activities like the Korean nationality etiquette, the handicraft production and the characteristic diet making, encourage the masses to participate and experience in person. Enterprises can be united to provide equipment, prop and materials and people can buy products made by them.

\section{Create and Repair the Basic Space for the Survival and Development of the Traditional Music Culture of Korean Nationality}

The government should pay adequate attention to the new rural construction and repair the broken agricultural social community of the Korean nationality. In recent years, many farmers of the Korean nationality have gone abroad to work and then purchase house and live in the southern coastal cities after coming back, but most of them don't become the citizens of those cities and they are in the edge of the urban mainstream culture. Because their genetic basis, social basis and economic basis are still in the hometown, they can be attracted to become the new force of new rural construction and ethnic culture construction through constructing the ethnic villages and implementing the policies. Meanwhile, the development of urban economy in the Korean nationality should be grasped. Nowadays, many farmers living in the cities become vagrants because they neither work on agriculture nor work in the city. It gives no cause for much criticism to organize surplus rural labor to work abroad, but it is not promising for a nationality to totally rely on the out-migration for work. We must take powerful measures to change their living styles, improve the investment environment, dwelling environment, employment environment and humanistic environment and develop the urban ethnic economy so as to breed urban new type of ethnic culture.

\section{Restore the Living Condition of Folk Performances in the Korean Nationality}

In the lengthy and arduous farming life, the people of Korean nationality have created colorful songs and dances as well as folk games and adept in expressing their emotional world through songs and dances in many occasions. Folk musical instruments like Dongxiao, Penxiang, flute, Erhu, long drum, round drum and $\mathrm{Xi}$ and Nongyue dance, Shanzi dance, Dingshui dance, Dao dance and masquerades are displayed in the exhibition hall through videos, projection and person models. The audience can appreciate the videos of different themes in the exhibition hall. The folk performances not only create and develop the cultural features of the Korean nationality but also promote the interpersonal communication and strengthen the cohesion between people.

\section{E. Strengthen the Construction of Ethnic Museum and Carry out the Academic Research of the Korean Nationality}

Extensive and in-depth academic research and high specialized level are the basis to create the unique culture brand of the Korean nationality. The museum can be used to create folk exhibition with high specialized level and popular among the masses. Therefore, the museum is a social educational institution and has the value of academic research. The academic research should be regarded as the core element to support and provide power for the development of museum. The "civilian" culture is mainly researched in the folk investigation of ethnology. The in-depth understanding of civilian culture still and must needs the field investigation. The National Folk Museum of Korea sends experts to live for some time and even one year in the rural areas and do project research as well as record, preserve, refer to and use the human landscape and folkways through the folk investigation, applying the research results in the display and the research on the ethnic culture, which greatly improve the display level and enrich the cultural connotation of the museum.

The folk museum of Korean nationality in Heilongjiang should refer to the development concept of the National Folk Museum of Korea, strengthen the academic research, combine the modern culture with the traditional culture and provide intellectual support for the development of traditional culture. Firstly, carry out the extensive folk investigation to excavate the materials of traditional folk culture, rescue the endangered traditional culture and record the evolution and development of traditional culture, excavate the trace of cultural changes. Besides, the horizon should be broadened to pay attention to the relationship between the culture in the Korean peninsula and the culture of Chinese Korean nationality, and then acquire abundant first hand information. Secondly, cooperate with other scientific research institutions to formulate the project concerning the traditional culture of the Korean nationality and the operation and management of museum, promote mutual operation and supplement each other to create a strong academic and management team through exchange learning, academic forum and exchange visits of scholars. Thirdly, pay attention to the information feedback of the audience and design questionnaires, welcoming the audiences to give valuable suggestions. Strengthen the research on the audience and understand their ideas through extensive investigations. Activities and service contents of the museum should be adjusted according to the demands of audience. The activities in the museum should meet the demands of stratums, the contents and service should cover the masses at different ages and the disabled. Finally, the folk culture of Korean nationality will satisfy the audience and the research results are popular among them. 
F. Actively Support the Cause of Ethnic Education and Let the Inheritance of Ethnic Culture Have Qualified Successors

- Implement the policy of ethnic education, pay attention to the cultural chauvinism trend and avoid obliterating the particularity of ethnic education under the slogan of "be all equal" as well as actively support the sound development of ethnic education in funds and policies.

- Strengthen the bilingual education and give priority to teachers of the Korean nationality to create the atmosphere of ethnic language in the school.

- Strengthen the traditional music education of the school. The traditional music class of the Korean nationality should be provided in the school to teach students one or two national instruments; establish traditional music clubs among students to hold artistic performance on campus regularly.

- Special departments should be set up in the school to carry out the psychological counseling for the stay-athome children through the combination of ideological education and folk music and art education, promoting the physical and psychological health through the beauty of music and art. Attentions should be paid to the education and training of the adolescent, especially carry out the traditional cultural education for children of the Korean nationality. Correct moral outlook and values can be trained through the edification of traditional education, which can effectively prevent the bad consciousness like the money worship and the hedonism. It is important for the stay-at-home children in the clustering area of the Korean nationality and an effective supplement of the family education with the traditional concept.

\section{G. Actively Carry out the Folk Music and Art Activities for the Masses}

- Management organizations and systems related to the music and art activities of the Korean nationality must be improved. All levels of management departments related to the art and culture of Korean nationality should endeavor to explore and research the construction and development of the urban ethnic music culture, exert the function of art troupe formed by the elder in inheriting the culture at the same time build cultural communities formed by people at all ages like the children's art troupe, the young art troupe and the youth art troupe. Various traditional music performances and competitions should be organized to stimulate the development of ethnic music culture.

- The original cultural facilities and entertainment venues should be restored and improved. The music and art activities for the masses are brought into the new rural construction to improve the value idea of national musical culture and strengthen the national cohesion.

- Administrative departments like the museum of art and the cultural center of the Korean nationality should research and explore the construction of urban national music culture and exert the function of art troupe formed by the elder in inheriting the culture. Clubs and organizations formed by people at all ages like the children's art troupe, the young art troupe and the youth art troupe should be established in some qualified towns to organize various forms of performances and competitions.

\section{CONCLUSION}

To sum up, in order to protect and inherit the traditional culture, it is necessary to follow the development law of things. The only right way is to develop it instead of attempting and accomplishing nothing when it is disappearing. The traditional music culture of the Korean nationality in Yanbian of Heilongjiang also faces the "pain" in the period of social transition. It can thrive through keeping pace with the social development, actively absorbing and referring to the diversified development mode of modern music, breaking through itself as well as developing a new space.

\section{REFERENCES}

[1] Li Kan. Advantages and Disadvantages of the Traditional Korean Nationality Music [J], Journal of Korean Nationality Music, 2009(4)

[2] Liu Zhiwei. Inheritance and Development of the Korean Nationality Music in Tongjiang [J], Journal of Tongjiang Normal University, 2011(5)

[3] Jin Chengjun. Current Situation and Prospect of the Traditional Korean Nationality Music - Centering on the Preservation of Traditional Music [J], Chinese Music, 2003(2):79-81

[4] Li Zongtian. Discussion on How to Protect and Inherit the Traditional Korean Nationality Music Culture [J], Brand: Theory Monthly, 2010(11):176-177 